Published in final edited form as: Prog Neuropsychopharmacol Biol Psychiatry. 2009 April 30; 33(3): 398-402. doi:10.1016/j.pnpbp. 2008.09.010.

\title{
Antidepressant-like effects of nicotine and reduced nicotinic receptor binding in the Fawn-Hooded rat, an animal model of co- morbid depression and alcoholism
}

\author{
Yousef Tizabia, ${ }^{\star}$, Bruk Getachew ${ }^{a, 1}$, Amir H. Rezvani ${ }^{b}$, Sheketha R. Hauser ${ }^{a}, 1$, and David H. \\ Overstreet $^{\mathrm{C}}$ \\ aDepartment of Pharmacology, Howard University College of Medicine, Washington, DC 20059, \\ United States \\ ${ }^{b}$ Department of Psychiatry and Behavioral Sciences, Duke University Medical Center, Durham, NC \\ 27710, United States \\ 'Department of Psychiatry, University of North Carolina, Chapel Hill, NC 27599, United States
}

\begin{abstract}
A strong positive association between depression and alcoholism is evident in epidemiological studies. Curiously, the incidence of smoking (nicotine intake) is also very high among depressed individuals. Because neuronal nicotinic receptors have been implicated in mood regulation as well as in reinforcing effects of alcohol, it was of interest to determine whether inherent changes in these receptors may be manifested in an animal model that expresses both depressive-like characteristics and high alcohol intake. Thus, Fawn-Hooded (FH) rats along with their control ACI rats were used to measure the density of the high affinity nicotinic receptor in discrete brain regions. Furthermore, the effects of acute and chronic nicotine on depressive-like characteristics of FH rats were also evaluated. Measurements of $\left[{ }^{3} \mathrm{H}\right]$ cytisine binding (selective for $\alpha 4 \beta 2$ nicotinic receptor subtype) revealed a reduction in these receptors only in the striatum of $\mathrm{FH}$ rats, a result very similar to that observed in selectively-bred alcohol-preferring (P) rats. Administration of nicotine acutely $(0.4 \mathrm{mg} /$ $\mathrm{kg}, \mathrm{sc}$ ) resulted in a significant reduction of immobility in the forced swim test (FST) in FH rats only, implying an antidepressant-like effect of nicotine. Another group of FH rats were administered 0.4 $\mathrm{mg} / \mathrm{kg}$ nicotine (daily, sc) for 14 days and their behavior in the FST was evaluated $22-24 \mathrm{~h}$ after the last injection. In this case, nicotine also had a significant antidepressant-like effect in FH rats suggesting no tolerance to nicotine had occurred. The effects of nicotine on FST behavior are very similar to those observed in Flinders Sensitive Line rats, a putative animal model of depression. Together, these findings provide additional evidence for antidepressant-like effects of nicotine and strengthen the postulated association between striatal nicotinic receptors and high alcohol intake. Thus, nicotinic receptors could be suitable targets for the development of novel pharmacotherapy for treatment of depression and possibly alcoholism.
\end{abstract}

\section{Keywords}

Alcohol intake; Depressive-like behavior; FH rat model; Nicotine; Nicotinic receptors

\footnotetext{
(C) 2008 Elsevier Inc. All rights reserved.

* Corresponding author. Department of Pharmacology, College of Medicine, 520 W Street N.W., Howard University, Washington, DC 20059, United States. Tel.: +1 202806 9719; fax: +1 202806 4453. ytizabi@ howard.edu.

${ }^{1}$ Current address: Department of Psychiatry, Indiana University, Indianapolis, IN, USA.
} 


\section{Introduction}

Although significant progress in the pharmacotherapy of depression has been achieved in the past decades, the refractory cases, delays in response and side effects associated with current medications are among major medical challenges. Similarly, therapeutic approaches in treatment of alcoholism are far from ideal and are often complicated by the prevalent co-morbid occurrence of depression. Thus, understanding the biological substrates that could contribute to such co-morbidity may offer novel pharmacotherapy. Interestingly, Fawn-Hooded (FH) rats show both high alcohol intake and depressive characteristics (Rezvani et al., 2002,2007), rendering them a suitable animal model to investigate neurobiological substrates of co-morbid alcohol-depression condition. The FH/Wjd strain voluntarily consumes high amounts of alcohol (Rezvani et al., 1990,2002), shows innate exaggerated immobility in the forced swim test (Rezvani et al., 2002), and exhibits elevated corticosterone levels that are normalized with antidepressant treatment (Aulakh et al., 1993). These differences are observed not only in reference to other strains of rats, such as Wistar and Sprague-Dawley, but also in reference to other inbred strains, including the FH/Har and ACI strains (Overstreet et al., 1999).

Curiously, the incidence of smoking (nicotine intake) is very high among both alcoholics (Meyerhoff et al., 2006) and depressed individuals (see reviews: Glassman, 1993, Quattrocki et al., 2000). Whereas the reinforcing effects of nicotine may contribute to its simultaneous intake with alcohol (Tizabi et al., 2002, 2007), the postulated antidepressant effects of nicotine may contribute to its use in depressed individuals. It has been observed that chronic administration of nicotine or selective nicotinic agonist in the learned helplessness paradigm in rats may alleviate the depressive symptoms in these rats (Semba et al., 1998, Ferguson et al., 2000). We have demonstrated that acute or chronic intermittent administration of nicotine in Flinders Sensitive Line (FSL) rats, an animal model of depression (Overstreet et al., 2005a), alleviates their depressive symptoms as determined by reduction of their immobility in the forced swim test (FST) (Tizabi et al., 1999). Similar results were obtained by Djuric et al. (1999) following chronic oral intake of nicotine in FSL rats. We also observed that FSL rats had higher nicotinic receptor densities in several brain regions (as determined by $\left[{ }^{3} \mathrm{H}\right]$ cytisine binding in tissue homogenate) compared to their control, the Flinders Resistant Line (FRL) rats (Tizabi et al., 1999). Moreover, the antidepressant effects of nicotine in FSL rats could be blocked by pretreatment with the non-selective nicotinic receptor antagonist mecamylamine, strengthening the argument that the antidepressant effects of nicotine are mediated through nicotinic receptors (Tizabi et al., 2000).

A role for central nicotinic receptors in the reinforcing effects of alcohol has also been suggested by several animal studies. Thus, administration of mecamylamine either systemically (Blomqvist et al., 1996; Lê et al., 2000) or into the ventral tegmental area of rats (Ericson et al., 1998) markedly reduced ethanol intake and preference (see also Soderpalm et al., 2000; Lof et al., 2007) as well as ethanol-induced dopamine release in the nucleus accumbens (Tizabi et al., 2002, 2007, Ericson et al., 2008). Moreover, several clinical studies have reported a decrease in alcohol reinforcing effects following mecamylamine administration (Blomqvist et al., 2002; Chi and de Wit, 2003). Interestingly, alcohol-preferring (P) rats show a reduction of the high affinity nicotinic receptors in the striatum (Tizabi et al., 2001), which is in contrast to the increased number of these receptors seen in FSL rats. In this study we sought to determine whether high affinity nicotinic receptor densities in FH rats would resemble those of $\mathrm{P}$ or FSL rats. Moreover, it was of relevance to investigate whether nicotine may also act as an antidepressant in this strain. 


\section{Materials and methods}

\subsection{Animals and housing}

The Fawn-Hooded FH/Wjd (FH) and ACI/N (ACI) rats which serve as control model for FH rats were randomly selected from the breeding colonies maintained by brother-sister mating at the Center for Alcohol Studies at the University of North Carolina at Chapel Hill. As mentioned above, the inbred ACI/N strain drinks very little alcohol voluntarily and therefore is an ideal control for the inbred FH/Wjd rats (Li and Lumeng, 1984; Overstreet et al., 1999).

Adult male rats of approximately 80 days old and weighing 300-350 g were maintained in groups of 2-3 in plastic cages in a temperature $\left(22{ }^{\circ} \mathrm{C}\right)$ and humidity $(50 \%)$ controlled room with free access to food and water and a reversed 12:12 light:dark cycle (lights on at $1900 \mathrm{~h}$ ). The reversal of time cycle was to allow convenient measurement of the behavior during active (dark) phase of the light cycle. The treatment and care of the animals were carried out under an experimental protocol in accordance with NIH guidelines as approved by the Institutional Animal Care and Use Committee.

\subsection{Forced swim test (FST)}

Although the forced swim test was originally developed to test the efficacy of antidepressants, this test is also commonly used to assess the helplessness or depressive-like behavior in rodents, particularly those of inbred strains (Porsolt et al., 1977; Detke et al., 1995; Lucki, 1997; Tizabi et al., 1999; Rezvani et al., 2002; Overstreet et al., 2005a, 2008). This test was conducted in a cylindrical tank $60 \mathrm{~cm}$ tall and $18 \mathrm{~cm}$ diameter, containing enough $25^{\circ} \mathrm{C}$ water so that the rat could not touch the bottom with its hind paws. The animal was placed in the water ( $20 \mathrm{~min}$ after the injection for acute studies, 20-24 h after the last injection for the chronic studies) and the amount of time it was immobile was recorded over a single $5 \mathrm{~min}$ period by an experienced observer blind to treatment condition. Immediately after the test the animal was dried and returned to its home cage. It should be mentioned that many studies using the forced swim test (FST) for screening the antidepressant efficacy of a compound subject the rats to $15 \mathrm{~min}$ "pretest" where the rats are exposed to inescapable water tank as during the 5 min actual test. This pre-exposure in actuality induces the learned helplessness in that $24 \mathrm{~h}$ later the rats manifest significant amount of immobility against which potential antidepressants are evaluated. However, FH rats are genetically selected for their manifestation of the behavioral despair and have been inbred through many generations whereby they may be considered an inbred animal model of behavioral despair as reflected in their exaggerated immobility in the FST compared to their control the ACI rats. Thus, the efficacy of an antidepressant may be evaluated in these animals without the need for pretest. This modified test has been used repeatedly in our laboratory (e.g., Tizabi et al., 1999; Rezvani et al., 2002; Overstreet et al., 2005a,b, 2008; Getachew et al., 2008).

Since the biological half-life of nicotine is approximately $90 \mathrm{~min}$, it is unlikely that any nicotine would be present in the body $20-24 \mathrm{~h}$ after the last nicotine injection when the animals were tested following chronic nicotine administration. Although, the major nicotine metabolite cotinine may still be present in the plasma due to much longer half-life of this compound, it is unlikely that the behavioral effects could be attributed to cotinine as it is well established the major behavioral effects observed following nicotine administration are attributed to nicotine itself and not its metabolite cotinine (James et al., 1998; Benowitz, 2008; Pehrson et al., 2008).

\subsection{Locomotor activity (LCA) monitoring}

In order to exclude the possibility that the differential effect of nicotine in the FST in the FH and ACI lines could be attributed to any non-specific locomotor effects of nicotine, we 
evaluated the acute effects of nicotine in an open field locomotor activity test. In this test, 20 min after nicotine injection the rats were placed in a monitoring box $(60 \times 60 \mathrm{~cm})$ that was divided in 16 squares $(10 \times 10 \mathrm{~cm}$ each $)$ and the number of squares crossed was scored over a 5 min period.

\subsection{Drug administration}

For acute studies, -(-)nicotine bitartrate (Sigma, St. Louis, US) was dissolved in saline and was administered subcutaneously $(0.1 \mathrm{ml} / 100$ g.b.w.). The nicotine dose was adjusted such that $0.4 \mathrm{mg} / \mathrm{kg}$ nicotine base was injected. The animals were tested $20 \mathrm{~min}$ after a single injection. For chronic studies, $0.4 \mathrm{mg} / \mathrm{kg}$ nicotine was administered (sc) once daily for 14 consecutive days. In chronic treatments, the swim test was performed $20-24 \mathrm{~h}$ after the last injection. Controls were administered isotonic saline $(0.1 \mathrm{ml} / 100$ g. b.w. $)$.

\subsection{Tissue collection}

Following their adaptation to the housing environment for one week, $8 \mathrm{FH}$ rats and 8 agematched ACI rats were decapitated between $10 \mathrm{AM}$ and 2:00 PM. The order of killing was alternated between the groups. Brains were quickly removed and frozen on dry ice and stored at $-80{ }^{\circ} \mathrm{C}$ until dissected and assayed for receptor density.

\subsection{Brain dissection and determination of nicotinic receptors}

Brains were thawed and kept on an ice-cold plate. Frontal cortex (up to the genu of corpus callosum and excluding the olfactory bulb and olfactory tubercle), cerebral cortex (the rest of the cortex, left and right hemisphere), striatum (bilateral), hippocampus (bilateral), midbrain (containing the thalamus), colliculi (superior and inferior), and cerebellum were dissected as described previously and stored frozen at $-80^{\circ} \mathrm{C}$ before measuring nicotinic receptor binding (Tizabi et al., 1999,2000). Tissue was homogenized in ice-cold $50 \mathrm{mM}$ Tris- $\mathrm{HCl}$ buffer (pH 7.0 at room temperature). The tissue homogenate was centrifuged at $38,000 \times \mathrm{g}$ for $12 \mathrm{~min}$ at $4{ }^{\circ} \mathrm{C}$. The pellet was washed twice by suspension in fresh buffer and centrifuged again. Aliquots of homogenate equivalent to approximately 10 to $20 \mathrm{mg}$ tissue were used for determination of $\left[{ }^{3} \mathrm{H}\right]$ cytisine binding which is selective for $\alpha_{4} \beta_{2}$ nicotinic receptor subtype (Flores et al., 1992). Approximately $4 \mathrm{nM}\left[{ }^{3} \mathrm{H}\right]$ cytisine (38.6 Ci/mmol, Perkin-Elmer, Boston, MA) was incubated in a final volume of $0.25 \mathrm{ml}$ at $2{ }^{\circ} \mathrm{C}$ for $75 \mathrm{~min}$. Non-specific binding was obtained in the presence of $100 \mu \mathrm{M}(-)$-nicotine bitartrate. These concentrations used to determine the maximal receptor binding are based on original description by Pabreza et al. (1991) and a number of our own previous studies (Tizabi et al., 1999,2000). Membrane-bound $\left[{ }^{3} \mathrm{H}\right]$ cytisine was separated from free ligand by filtration in a Brandel cell harvester using Brandel GF/B filter paper (soaked in $0.5 \%$ polyethylenimine to reduce non-specific binding). Samples were run in triplicate for both total and non-specific binding. Final density was expressed per $\mathrm{mg}$ protein which was determined by using the Pierce BCA kit (Pierce Chemical Company, Rockford, IL).

\subsection{Statistical analysis}

Binding data comparing the FH and ACI rats were analyzed by the Student's $t$ test. Behavioral parameters were analyzed by two-way ANOVA. The ANOVAs were followed by NewmanKeuls post hoc test when a significant main effect was indicated. All analyses were two-tailed and used an alpha of 0.05 or less to determine significance. 


\section{Results}

\section{1. $\left[{ }^{3} \mathrm{H}\right]$ cytisine binding}

Table 1 presents the $\left[{ }^{3} \mathrm{H}\right]$ cytisine binding in 7 discrete brain regions of $\mathrm{ACI}$ and $\mathrm{FH}$ rats. Binding densities in the two strains were very similar in 6 of the regions. However, in the striatum the concentration of the high affinity nicotinic receptors was significantly lower (approximately 27\%) in the FH rats compared to ACI $(t=2.64, p<0.05)$.

\subsection{Effects of acute nicotine}

Compared with their control counterpart, the FH rats demonstrated an enhanced depressivelike behavior in FST. However, the immobility of FH in FST was significantly $F[1,28]=10.12$, $p<0.01$ reduced by an acute administration of $0.4 \mathrm{mg} / \mathrm{kg}$ nicotine (Fig. 1). The same dose of nicotine did not have a significant effect on FST in ACI rats. Consistent with the selective effect of nicotine in the FH rats, the interaction effect was significant $(F[1,28]=12.09, p<0.01)$. Interestingly, the $0.4 \mathrm{mg} / \mathrm{kg}$ acute nicotine resulted in significant decrease $(p<0.01)$ in the open field locomotor activity in both FH and ACI rats (Table 2).

\subsection{Effects of chronic nicotine}

Fig. 2 presents the effects of chronic nicotine administration on swim test immobility in ACI and FH rats. Administration of nicotine $(0.4 \mathrm{mg} / \mathrm{kg})$ for 14 consecutive days resulted in a significant reduction in swim test immobility in FH rats only. The effects of chronic nicotine were very similar to those observed in the acute studies suggesting that no tolerance to the antidepressant-like effects of nicotine developed. Thus, the FH rats were more immobile than the ACI rats $(F[1,28]=4.63, p<0.05)$ and nicotine had a significant reducing effect on swim test immobility $(F[1,28]=7.04, p<0.01)$. Again, consistent with nicotine having a selective effect on the $\mathrm{FH}$ rats, the interaction was significant $(F[1,28]=9.30, p<0.01)$.

\section{Discussion}

The binding studies revealed a significant reduction of the high affinity nicotinic receptors only in the striatum of FH rats compared to their control, the ACI rats. This finding bears a striking similarity to what was observed in alcohol-preferring $\mathrm{P}$ rats in comparison to the alcohol nonpreferring (NP) rats (Tizabi et al., 2001). Thus, it may be suggested that the shared high intake for alcohol in P and FH rats is likely to be influenced by a common neurochemical substrate, i.e. a reduction of high affinity striatal nicotinic receptors. Although a role for nucleus accumbens shell, part of the ventral striatum, in drugs of abuse including alcohol is well established (Koob and Bloom, 1988), various other studies indicate also a role for the dorsal striatum in alcohol consumption (Nestby et al., 1999; Yoshimoto et al., 1999). Given that the nicotinic receptors are primarily located presynaptically and are known to affect the release of a variety of neurotransmitters (Wonnacott, 1997), it would be of interest to determine whether manipulation of striatal nicotinic receptors may influence alcohol intake. Previous studies reported that nicotine treatment frequently leads to the increase in alcohol intake (Clark et al., 2001; Lê et al., 2003; Soderpalm et al., 2000) but did not implicate a brain site or specific roles for selective nicotinic receptor subtype(s). Interestingly, a recent study indicates that administration of varenicline, a partial agonist at high affinity nicotinic receptor, reduces alcohol seeking and consumption in rats (Steensland et al., 2007). However, the exact site(s) of action of varenicline have yet to be identified. It is also of relevance to note that although several nicotinic receptor subtypes are present in ventral tegmental area the alpha3 containing subunit may be most directly involved in alcohol rewarding effects (Jerlhag et al., 2006).

In addition to their possible role in alcohol intake and addiction, substantial evidence suggests involvement of nicotinic receptors in mood regulation and several neuropsychiatric disorders. 
Indeed, an antidepressant-like effect of nicotine has been demonstrated in a variety of animal (Semba et al., 1998; Ferguson et al., 2000; Djuric et al., 1999; Tizabi et al., 1999, 2000) and some human studies (Glassman 1993; Salin-Pascual et al., 1996; Gilbert 1996, Salin-Pascual and Drucker-Colin 1998). Thus, the observed antidepressant-like effects of nicotine in FH rats in this study further support a role for nicotinic receptors in mood regulation. Nicotine in some strains of rats that do not manifest exaggerated immobility in the FST may decrease this immobility (Djuric et al.,, 1999). However, we have found that under present paradigm, nicotine by itself is not decreasing the immobility in the ACI control rats. This finding is very similar to what we had observed in FRL rats that act as control for FSL rats (Tizabi et al., 1999). A possible explanation for our observation in ACI rats is that the immobility in these animals might be at its trough (floor) level and hence a further reduction in this parameter might not be easily achieved with nicotine. Moreover, it is important to note that the effects of nicotine in forced swim test (suggestive of antidepressant-like effect) are not due to a general stimulant effect of nicotine. Indeed, in this study as well as the previous one with FSL rats, acute nicotine administration resulted in decreases in locomotor activities in the open field whereas the same treatment resulted in decreases in immobility in the FST (Table 2 and Tizabi et al., 1999).

A remarkable feature of the $\mathrm{FH}$ rats is their dual expression of high alcohol intake and depressive-like characteristics resembling the co-morbid occurrence of alcoholism and depression in human populations. Various theories have attempted to explain the association between alcoholism and depression. These include common genetic susceptibility; an antidepressant-like effect of alcohol initially that leads to alcohol dependence; or development of depression following excessive alcohol use (see Getachew et al., 2008). However, the results of a study with progenies of FH and ACI rats suggest separate genetic controls for the alcohol intake and depressive-like characteristics in FH rats (Rezvani et al., 2002, 2007). Although some evidence in support of alcohol-induced depressive-like behavior in animal studies have been provided (Getachew et al., 2008), there is also evidence that WKY rats, a putative animal model of depression would consume more alcohol than their control the Wistar rats when given a free choice (Jiao et al., 2006). Hence, it would be of interest to determine how manipulation of either behavior (alcohol intake or depressive-like characteristic) of FH rats might affect the other behavior. Curiously, it was reported recently (Overstreet et al., 2005b) that chronic treatment with fluoxetine, a well-known antidepressant, resulted in a reduction of swim test im-mobility but no change in alcohol intake in the FH rats. It should be noted, however, that distinct neurobiological substrate may be responsible for similar behavior in different species and hence extrapolation form studies in FH rats to human conditions have to be carefully considered. Certainly, further elucidation of the complex interaction of nicotine with both alcohol drinking and depressive-like behavior and involvement of nicotinic receptors in these interactions is necessary.

\section{Conclusion}

In summary, these findings indicate that the high affinity nicotinic receptors are reduced in the striatum of the FH rats similar to what was observed in alcohol-preferring $\mathrm{P}$ rats and provide additional evidence for antidepressant-like property of nicotine in this strain. Further studies on pharmacotherapy of nicotinic agents and specific role of nicotinic receptors in depression and alcoholism are warranted.

\section{Acknowledgments}

Supported by NIH/NIGMS 2S06GM08016-38. 


\section{Abbreviations}

$\begin{array}{ll}\text { FH } & \text { fawn-hooded } \\ \text { FRL } & \text { Flinders Resistant Line } \\ \text { FSL } & \text { Flinders Sensitive Line } \\ \text { FST } & \text { forced swim test } \\ \text { NP } & \text { non-preferring } \\ \text { P } & \text { alcohol-preferring }\end{array}$

\section{References}

1. Aulakh CS, Hill JL, Murphy DL. Attenuation of hypercortisolemia in fawn-hooded rats by antidepressant drugs. Eur J Pharmacol 1993;240:85-8. [PubMed: 8405126]

2. Benowitz NL. Clinical pharmacology of nicotine: implications for understanding, preventing, and treating tobacco addiction. Clin Pharmacol Ther 2008;83:531-41. [PubMed: 18305452]

3. Blomqvist O, Ericson M, Johnson DH, Engel JA, Soderpalm B. Voluntary ethanol intake in the rat: effects of nicotinic acetylcholine receptor blockade or subchronic nicotine treatment. Eur J Pharmacol 1996;314:257-67. [PubMed: 8957244]

4. Blomqvist O, Hernandez-Avila CA, Van Kirk J, Rose JE, Kranzler HR. Mecamylamine modifies the pharmacokinetics and reinforcing effects of alcohol. Alcohol Clin Exp Res 2002;26:326-31. [PubMed: 11923584]

5. Clark A, Lindgren S, Brooks SP, Wattson WP, Little LJ. Chronic infusion of nicotine can increase operant self-administration of alcohol. Neuropharm 2001;41:108-17.

6. Chi H, de Wit H. Mecamylamine attenuates the subjective stimulant-like effects of alcohol in social drinkers. Alcohol Clin Exp Res 2003;27:780-6. [PubMed: 12766622]

7. Detke MJ, Rickels M, Lucki I. Active behaviors in the rat forced swimming test differentially produced by serotonergic and noradrenergic antidepressants. Psychopharm 1995;121:66-72.

8. Djuric VJ, Dunn E, Overstreet DH, Dragomir A, Steiner M. Antidepressant effects of ingested nicotine in female rats of Flinders Resistant and Sensitive Lines. Physiol Behav 1999;67:533-7. [PubMed: 10549890]

9. Ericson M, Blomqvist O, Engel JA, Soderpalm B. Voluntary ethanol intake in the rat and the associated accumbal dopamine overflow are blocked by ventral tegmental mecamylamine. Eur J Pharmacol 1998;358:189-96. [PubMed: 9822883]

10. Ericson M, Lof E, Stomberg R, Chau P, Soderpalm B. Nicotinic acetylcholine receptors in the anterior, but not posterior, VTA mediate ethanol induced elevation of accumbal dopamine levels. J Pharmacol Exp Ther 2008;326:76-82. [PubMed: 18369179]

11. Ferguson SM, Brodkin JD, Lloyd GK, Menzaghi F. Antidepressant-like effects of the subtypeselective nicotinic acetylcholine receptor agonist, SIB-1508Y, in the learned helplessness rat model of depression. Psychopharm 2000;152:295-303.

12. Flores CM, Rogers SW, Pabreza LA, Wolfe BB, Kellar KJ. A subtype of nicotinic cholinergic receptor in rat brain is composed of alpha 4 and beta 2 subunits and is up-regulated by chronic nicotine treatment. Mol Pharmacol 1992;41:31-7. [PubMed: 1732720]

13. Getachew B, Hauser SR, Taylor RE, Tizabi Y. Desipramine blocks alcohol-induced anxiety- and depressive-like behaviors in Wistar-Kyoto (WKY) and Wistar rats. Pharm Biochem Behav 2008;91:97-103.

14. Gilbert DG. Depression, smoking, and nicotine: toward a bioinformational situation by trait model. Drug Dev Res 1996;38:267-77.

15. Glassman AH. Cigarette smoking: implications for psychiatric illness. Am J Psychiatr 1993;150:54653. [PubMed: 8465868]

16. James H, Tizabi Y, Taylor RE. Rapid method for simultaneous measurement of nicotine and cotinine in urine and serum by gas chromatography-mass spectrometry. J Chromatogr B 1998;708:87-93. 
17. Jerlhag E, Grotli M, Luthman K, Svensson L, Engel JA. Role of subunit composition of central nicotinic acetylcholine receptors for the stimulatory and dopamine-enhancing effects of ethanol. Alcohol Alcohol 2006;41:486-93. [PubMed: 16799162]

18. Jiao X, Paré WP, Tejani-Butt SM. Alcohol consumption alters dopamine transporter sites in WistarKyoto rat brain. Brain Res 2006;1073-1074:175-82.

19. Koob GF, Bloom FE. Cellular and molecular mechanisms of drug dependence. Science 1988;242:715-23. [PubMed: 2903550]

20. Lê AD, Corrigall WA, Watchus J, Harding S, Juzytsch W, Li TK. Involvement of nicotinic receptors in alcohol self-administration. Alcohol Clin Exp Res 2000;24:155-63. [PubMed: 10698366]

21. Lê AD, Wang A, Harding S, Juzytsch W, Shaham Y. Nicotine increases alcohol self-administration and reinstates alcohol seeking in rats. Psychopharm 2003;168:216-21.

22. Li TK, Lumeng L. Alcohol preference and voluntary alcohol intakes of inbred rat strains and the National Institutes of Health heterogeneous stock of rats. Alcohol Clin Exp Res 1984;8:485-6. [PubMed: 6391261]

23. Lof E, Olausson P, de Bejczy A, Stomberg R, McIntosh JM, Taylor JR, et al. Nicotinic acetylcholine receptors in the ventral tegmental area mediate the dopamine activating and reinforcing properties of ethanol cues. Psychopharm 2007;195:333-43.

24. Lucki I. The forced swimming test as a model for core and component behavioral effects of antidepressant drugs. Behav Pharmacol 1997;8:523-32. [PubMed: 9832966]

25. Meyerhoff DJ, Tizabi Y, Staley JK, Durazzo TC, Glass JM, Nixon SJ. Smoking comorbidity in alcoholism: neurobiological and neurocognitive consequences. Alcohol Clin Exp Res 2006;30:25364. [PubMed: 16441274]

26. Nestby P, Vanderschuren LJ, De Vries TJ, Mulder AH, Wardeh G, Hogenboom F, et al. Unrestricted free-choice ethanol self-administration in rats causes long-term neuroadaptations in the nucleus accumbens and caudate putamen. Psychopharm 1999;141:07-314.

27. Overstreet DH, Rezvani AH, Parsian A. Behavioural features of alcohol-preferring rats: focus on inbred strains. Alcohol Alcohol 1999;34:378-85. [PubMed: 10414614]

28. Overstreet DH, Friedman EF, Mathe AM, Yadid G. The Flinders Sensitive Line rat: a selectively bred putative animal model of depression. Neurosci Biobehav Rev 2005a;29:739-59. [PubMed: 15925699]

29. Overstreet DH, Rezvani AH, Parsian A. Chronic fluoxetine reduces swim test immobility but not alcohol intake in fawn-hooded rat, an animal model of comorbid depression/alcoholism. Soc Neurosci Abst. 2005b

30. Overstreet DH, Stemmelin J, Griebel G. Confirmation of antidepressant potential of the selective beta3 adrenoceptor agonist amibegron in an animal model of depression. Pharmacol Biochem Behav 2008;89:623-6. [PubMed: 18358519]

31. Pabreza LA, Dhawan S, Kellar KJ. $\left[{ }^{3} \mathrm{H}\right]$ cytisine binding to nicotinic cholinergic receptors in brain. Mol Pharmacol 1991;39:9-12. [PubMed: 1987453]

32. Pehrson AL, Philibin SD, Gross D, Robinson SE, Vann RE, Rosecrans JA, et al. The effects of acute and repeated nicotine doses on spontaneous activity in male and female Sprague Dawley rats: analysis of brain area epibatidine binding and cotinine levels. Pharmacol Biochem Behav 2008;89:424-31. [PubMed: 18313740]

33. Porsolt D, Bertin A, Jalfre M. Behavioral despair in mice: a primary screening test for antidepressants. Arch Int Pharmacodyn Ther 1977;229:327-36. [PubMed: 596982]

34. Quattrocki E, Baird A, Yurgelun-Todd D. Biological aspects of the link between smoking and depression. Harv Rev Psychiatry 2000;8:99-110. [PubMed: 10973935]

35. Rezvani AH, Overstreet DH, Janowsky DS. Genetic serotonin deficiency and alcohol preference in the fawn hooded rats. Alcohol Alcohol 1990;25:573-5. [PubMed: 2088356]

36. Rezvani AH, Parsian A, Overstreet DH. The fawn-hooded (FH/Wjd) rat: a genetic animal model of comorbid depression and alcoholism. Psychiatr Genet 2002;12:1-16. [PubMed: 11901354]

37. Rezvani AH, Overstreet DH, Cleaves M, Parsian A. Further genetic characterization of the fawnhooded (FH/Wjd) rat, an animal model of comorbid depression and alcoholism. Psychiat Genet 2007; $17: 77-83$. 
38. Salin-Pascual RJ, Rosas M, Jimenez-Genchi A, Rivera-Meza BL, Delgado-Parra V. Antidepressant effect of transdermal nicotine patches in nonsmoking patients with major depression. J Clin Psychiatry 1996;57:387-9. [PubMed: 9746444]

39. Salin-Pascual RJ, Drucker-Colin R. A novel effect of nicotine on mood and sleep in major depression. NeuroReport 1998;9:57-60. [PubMed: 9592048]

40. Semba J, Mataki C, Yamada S, Nankai M, Toru M. Antidepressant like effects of chronic nicotine on learned helplessness paradigms in rats. Biol Psychiatr 1998;43:389-91.

41. Soderpalm B, Ericson M, Olausson P, Blomqvist O, Engel JA. Nicotinic mechanisms involved in the dopamine activating and reinforcing properties of ethanol. Behav Brain Res 2000;113:85-96. [PubMed: 10942035]

42. Steensland P, Simms JA, Holgate J, Richards JK, Bartlett SE. Varenicline, an alpha4beta2 nicotinic acetylcholine receptor partial agonist, selectively decreases ethanol consumption and seeking. Proc Natl Acad Sci USA 2007;104:12518-23. [PubMed: 17626178]

43. Tizabi Y, Overstreet DH, Rezvani AH, Louis VA, Clark E Jr, Janowsky DS, et al. Antidepressant effects of nicotine in an animal model of depression. Psychopharm 1999;142:193-9.

44. Tizabi Y, Rezvani AH, Russell LT, Tyler KY, Overstreet DH. Depressive characteristics of FSL rats: involvement of central nicotinic receptors. Pharmacol Biochem Behav 2000;66:73-7. [PubMed: 10837845]

45. Tizabi Y, Getachew B, Davila-Garcia M, Taylor RE. Alcohol preference: association with reduced striatal nicotinic receptors. Alcohol Alcohol 2001;36:318-22. [PubMed: 11468132]

46. Tizabi Y, Copeland RL Jr, Louis VA, Taylor RE. Effects of combined systemic alcohol and central nicotine administration into ventral tegmental area on dopamine release in the nucleus accumbens. Alcohol Clin Exp Res 2002;26:394-9. [PubMed: 11923594]

47. Tizabi Y, Bai L, Copeland RL Jr, Taylor RE. Combined effects of systemic alcohol and nicotine on dopamine release in the nucleus accumbens shell. Alcohol Alcohol 2007;42:413-6. [PubMed: 17686828]

48. Wonnacott S. Presynaptic nicotinic ACh receptors. Trends Neurosci 1997;20:92-8. [PubMed: 9023878]

49. Yoshimoto K, Kaneda S, Kawai Y, Ueda S, Takeuchi Y, Matsushita H, et al. Treating rats with 6hydroxydopamine induced an increase in voluntary alcohol consumption. Alcohol Clin Exp Res 1999;23(Suppl 4):2S-6S. [PubMed: 10235268] 


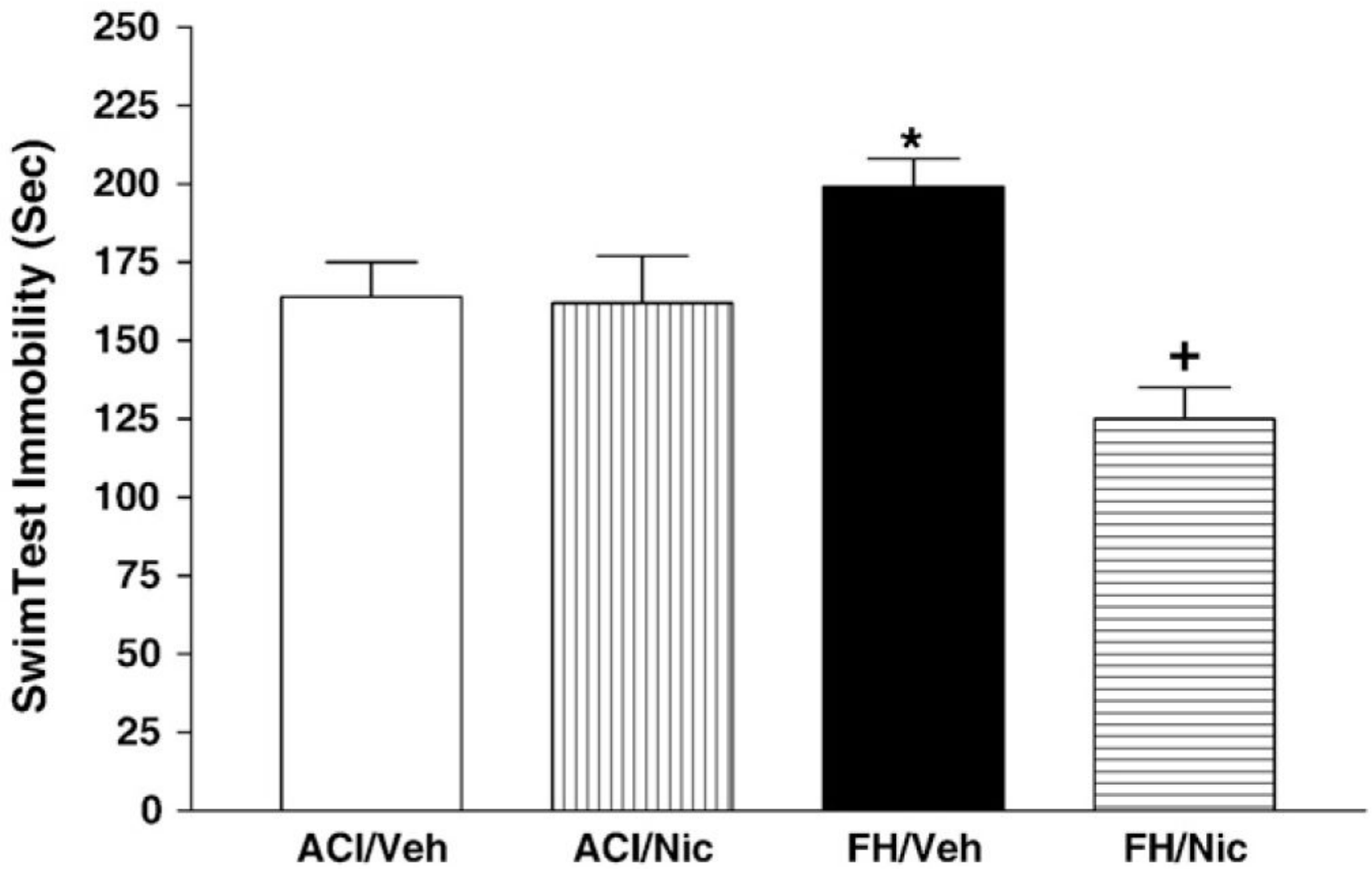

\section{*Significantly different from $\mathrm{ACl} / \mathrm{Veh}$ +Significantly different from $\mathrm{FH} /$ Veh}

Fig. 1.

Effects of acute nicotine administration $(0.4 \mathrm{mg} / \mathrm{kg}, \mathrm{sc})$ on swim test immobility in ACI and $\mathrm{FH}$ rats. The animals were tested $20 \mathrm{~min}$ after a single injection. Values are means $\pm \mathrm{SEM}$, $N=8$ /group. 


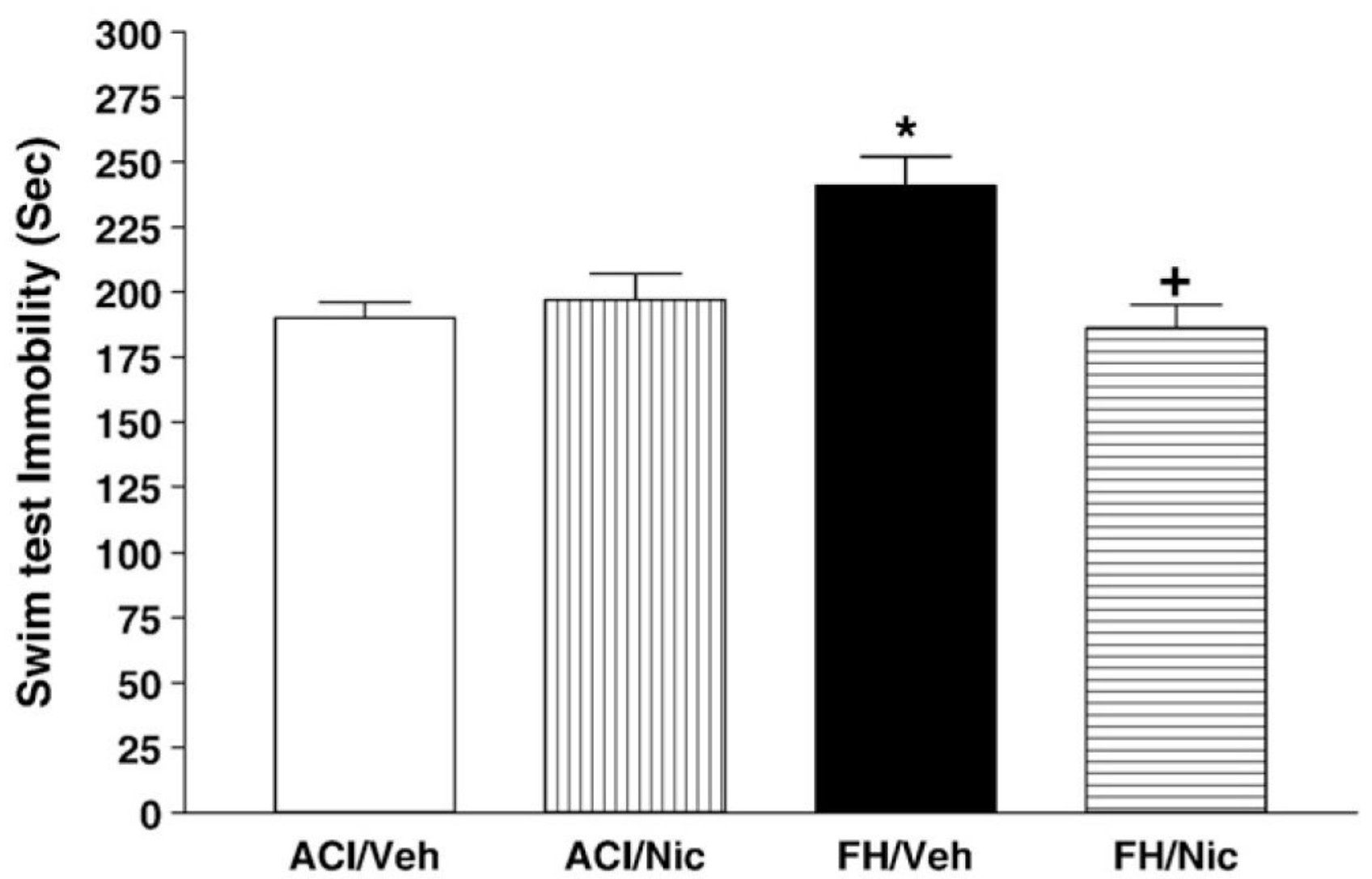

\section{*Significantly different from $\mathrm{ACl} /$ Veh +Significantly different from $\mathrm{FH} / \mathrm{Veh}$}

Fig. 2.

Effects of chronic nicotine administration $(0.4 \mathrm{mg} / \mathrm{kg} \mathrm{sc}$ daily for 14 days $)$ on swim test immobility in ACI and FH rats. The animals were tested $20-24 \mathrm{~h}$ after the last injection. Values are means $\pm \mathrm{SEM}, N=8$ /group. 


\section{Table 1}

$\left[{ }^{3} \mathrm{H}\right]$ Cytisine binding (fmol/mg protein) in discrete brain regions of ACI and $\mathrm{FH}$ rats.

\begin{tabular}{lll}
\hline Strain & & \\
\hline Region & ACI & FH \\
\hline Frontal cortex & $33.7 \pm 1.2$ & $31.9 \pm 1.3$ \\
Striatum & $44.0 \pm 3.0$ & $31.8 \pm 2.4^{*}$ \\
Hippocampus & $28.9 \pm 2.2$ & $32.0 \pm 1.9$ \\
Midbrain & $52.1 \pm 2.9$ & $48.6 \pm 3.3$ \\
Colliculi & $31.5 \pm 3.1$ & $28.1 \pm 2.1$ \\
Cortex & $32.5 \pm 2.5$ & $35.9 \pm 2.9$ \\
Cerebellum & $10.1 \pm 0.62$ & $10.2 \pm 0.91$ \\
\hline
\end{tabular}

Values are mean \pm SEM, $n=8 /$ group.

* $<0.05$ compared to ACI. 


\section{Table 2}

Effect of acute nicotine on open field locomotor activity in ACI and FH rats.

\begin{tabular}{lll}
\hline Strain & & \\
\hline Treatment & ACI & FH \\
\hline Vehicle & $99 \pm 6$ & $90 \pm 4$ \\
Nicotine & $41 \pm 7^{* *}$ & $41 \pm 3^{* *}$ \\
\hline
\end{tabular}

Animals were injected with nicotine $(0.4 \mathrm{mg} / \mathrm{kg}$ base, $\mathrm{sc})$ and were tested $20 \mathrm{~min}$ later in the open field locomotor activity cage. Values are mean \pm SEM, $n=6 /$ group.

**

p $<0.01$ compared to vehicle. 